\title{
The measuring instrument of primitive physics problem for junior high school students: Compilation and Research
}

\author{
Hongjun Xing ${ }^{1 *}$, Wenhui Gong², Peng Wang ${ }^{3}$, Yanfang Zhai', Yuping Zhao ${ }^{2}$ \\ ${ }^{1}$ College of Teacher Education, Capital Normal University, Beijing 100048, China \\ ${ }^{2}$ College of Education, Capital Normal University, Beijing 100048, China \\ ${ }^{3}$ Beijing $21^{\text {st }}$ Century International School, Beijing 100036, China \\ *Corresponding Author: xhjcnu1960@sina.com
}

(Received: 08/26/2020; Accepted: 12/19/2020; Published: 06/14/2021)

DOI: https://doi.org/10.37906/real.2021.1

\begin{abstract}
Problem representation in specific domains has raised great attention in the past years. In mainland China, research of the primitive physics problem teaching has been booming in the physics education domain recently. This study proposes six representations in the process of solving problems for middle school students, including abstraction representation, assignment representation, image representation, physics representation, methodology representation and mathematics representation. The measuring instrument of primitive physics problem for junior high school students was developed according to previous research and the principle of "Objectively Evaluating Subjective Questions". The participants were 113 grade nine students in mainland China. The results of confirmatory factor analysis confirm the effectiveness of the measuring instrument. A weak correlation between the measuring instrument of primitive physics problems and Lawson Classroom Test of Scientific Reasoning (LCTSR) was found. Therefore, we believe that the primitive physics problem solving ability is a unique ability which is different from the general reasoning ability. This study demonstrates that using the measuring instrument of primitive physics problem to measure junior high school students' ability of problem solving is promising.
\end{abstract}

Keywords: primitive physics problem; problem representation; measuring instrument

\section{Introduction}

In a traditional school framework, what distinguishes a student who manages to find the correct solution to a problem from one who does not (Johsua, S., \& Dupin, Jean-Jacques,1991)? The results show that students preferred to use a single solution method even though different solution methods were possible. This behavior can be attributed to their previous experience of solving practical problems in physics education. Despite our view of physics education in our introductory courses as being sensitive to the needs of students, many students exhibit low conceptual understanding and lessons are unable to capture their imagination (Enghag, M., Gustafsson, P., \& Jonsson, G., 2007). To eliminate the confusion which was brought by the traditional physics education, new types of problem have been developed in succession. 
Since the 1980s, researchers have begun to use physics knowledge as an example to discuss problem solving theories. Because the trend of problem-solving research is based on the theory of information processing, it advocates precise experimental design and strict control of experimental methods, and considering that the connection of psychological phenomena in the problem-solving process is linear and decisive, but many problems remain unsolved. For example, information processing theory is more effective in solving problems in knowledge-poor areas, but not effective in knowledge-rich areas, so it is worthy of further study. Therefore, problem solving is to provide students with a contextual physical process, from which we can reflect on students' level of thinking and understanding of concepts.

Based on the existing research on physical problem-solving and representation theory, this paper proposes the "self-organizing representation theory", which unifies the internal representation and external representation, and divides the problem-solving process of students into six stages. Based on this theory, the study compiled and tested the primitive physics problem for junior high school students. The tests met the evaluation criteria of "objective evaluation of subjective problems". Considering the fact that students start their formal physics education in grade 8 in mainland China, only knowledge of mechanics will be learned by 8th grade students. It is not until the 9th grade that students learn the knowledge of electricity systematically. Finally, this study selected 113 students from the ninth grade in mainland China for evaluation, and used the Lawson classroom test of scientific reasoning (LCTSR) as an evaluation tool to explore the correlation between students' ability to solve the primitive physics problem and ability of scientific reasoning.

\section{Literature Review}

\subsection{Physics problem}

Since physical phenomena are the root of physics, the research and design of subjective examination questions on physics have gradually increased in recent years. The context-rich questions used by Heller and Patricia at the University of Minnesota were written as short stories (Heller, P., \& Heller, K., 1999), including a reason for calculating a specific quantity, designed to promote classroom discussion and interaction, thereby improving learning ability. Rennie and Parker (Rennie, L. J., \& Parker, L. H., 1995) advocate that real-life context plays an important role in the ability to visualize a problem. Elizabeth and Chris (Whitelegg Elizabeth \& Edwards Chris.,2001) believe that real-life situations can help break students' prejudices that physics can only be applied in school examinations.

To challenge the exercise-heavy teaching method of physics education, the primitive physics problem has been introduced in the field of physics education in China recently(Hongjun Xing \& Yao Shi, 2016; Hongjun Xing \& Qingmei Chen, 2005; Hongjun Xing, 2007). The primitive physics problem refers to the physics problem that objectively exists and has not been fabricated in nature, society, and production. Different from the traditional physics exercises, the known and unknown quantities which are not given in the primitive physics problem need to be set by students according to their own requirements. For example, in the process of subway travel, passengers need to see the video advertisement on both sides of the tunnel through the window. How to set the video position so that passengers can see the TV screen along the way? In the above problems, students need to abstract the physical model, set the physical quantity independently to solve the problem. 


\subsection{Representation theory}

It has been established that the difficulty of solving a problem depends on the quality of its representation (Goldstein. E. Bruce., 2010). In physics, Simon et al. (D. P. Simon, \& H. A. Simon.,1978) have attributed the expert's physical intuition to the quality of the problem representation. The current consensus is that the expert's representation contains a great deal of qualitative knowledge (Michelene T. H. Chi, Paul J. Feltovich, \& Robert Glaser. ,1981). Kleer (J. De Kleer, 1977), for example, introduced both quantitative and qualitative components in the expert's representation of a physics problem where the qualitative component includes nonmathematical semantic descriptions of physical objects and their interactions.

The problem solver progress through four stages of representations as a learner solves a problem was addressed by McDermott and Larkin (McDermott, J, \& Larkin, J H., 1978). The first stage is the literal representation of the problem statement (containing relevant keywords) and the last stage is the algebraic representation that results once equations are produced. The middle two are the most important. The second stage is the naive representation, which contains the literal objects and their spatial relationships as stated in the problem and is often accompanied by a sketch of the situation (Larkin, J H., 1985). Such a representation and the accompanying sketch is naive because it can be formed by a person who is relatively ignorant of the domain of physics. The third stage is the scientific representation, which contains the idealized objects and physical concepts, which are necessary to generate the equations of the algebraic representation. This stage is related to the solution method. However, just as McDermott and Larkin (McDermott, J, \& Larkin, J H., 1978) stated, the utility of the two intermediate representations may be less clear. Meanwhile, the four representations are too rough to reflect the true problem-solving process of students. In mainland China, Liao (Boqin Liao, \& Xiting Huang, 1997) studied physical representation earlier and verified that the representation process is also applicable in China. Representation-State Theory (RST) of physical problem-solving was proposed in Zhu's (Zhu Deng, 2002) doctoral thesis, which provides some important enlightenment to us. Therefore, we introduce the primitive physics problem, highlighting the research direction of returning to physical phenomena and focusing on real-world application.

Based on the previous studies, the process of primitive physics problem solving includes the following six representations:

1) Abstraction Representation. Students can create mental entities for a higher level of organization of new concepts by the process of abstraction (Ainsworth, S., 2006). What information needs to be discarded and retained from the primitive physics problem requires the students to make their own decisions. The process of abstracting ideal objects from real physical phenomenon, a method that is extensively used in this stage, is to simplify and purify the process of object movement and sublimate it into an ideal state by imaginative, intuitive and logical thinking, so that the essence and nature of the primitive problem can be reflected more clearly.

2) Assignment Representation. Assignment representation is a unique representation type of primitive physics problem, which is rarely involved in the mechanical problem-solving process. Students should set physics quantities according to their needs, and list the known and unknown quantities. Intermediate quantities are also necessary at times to be set up, which appears in the process of solving problem, but they do not appear in the final equation. Certainly, the physics quantities set in this stage are not required to be consistent for the reason that there is no need for uniform and fixed assignments to solve problems. 
3) Image Representation. Image representation is included in both traditional exercises and original problem-solving processes. In general, the image representation of the primitive physics problem is completed by students, while the image representation process of traditional exercises sometimes needs to be completed by the students themselves, and sometimes is asked directedly by the problems.

4) Physics Representation. A major aspect for students to solve physics problems is to consider what major principle or conception can be applied to problems (Yerushalmi, E., Henderson, C., Heller, K., Heller, P., \& Kuo, V., 2007). The process of identifying and using physical conceptions and principles to solve problems refers to physics representation, which means students need to relate the primitive physics problem to the physical concepts and principles they have learned before.

5) Methodology Representation. In this stage, scientific methodology or specifically scientific methods should be identified by students to solve problems.

6) Mathematics Representation. The last solving process of the primitive physics problem is mathematics representation, which means a series of mathematical deduction steps, including column equation, solution equation, necessary mathematical transformation and approximation. Unlike other representations, the mathematics representation of the primitive physics problem is the same as those of traditional exercises and is more abstract than physics representation (McDermott, J, \& Larkin, J H., 1978).

As a good comparison, solving primitive physics problem contains six representations, while the traditional exercises often have only the last three representations.

\section{Research design}

\subsection{Participants}

Grade 9 students who came from mainland China participated in the present research. A total of two public middle schools were invited to enrolled in the project. Eventually, 113 students responded to the measuring instrument and 113 students were included in the final data analysis.

\subsection{Instruments}

3.2.1. The measuring instrument of primitive physics problem for junior high school students

An excellent measuring instrument not only has the higher ecological validity, but also reasonable criteria of rating. At present, most of the existing creative test instruments are rated step by step. The advantage of this rating approach is that it can examine students' abilities in depth, while the disadvantage is the instrument is more subjective. Generally, the measuring instruments which are internationally accepted are often objective questions followed by a number of possible answers. The objective questions have the accurate rating, but they may lack the advantage of subjective questions that could not measure the real aspects that are needed. Meanwhile, there are some factors of speculation in the objective questions, students still have a certain possibility of a correct answer theoretically, even if the student does not get the right answer completely. Obviously, the only way to avoid the shortcomings of the two kinds of questions is to combine the advantages of subjective questions with those of objective questions. Hence, we established the principle of Objectively Evaluating Subjective Questions, so the evaluation criteria of subjective question are linked to objectification.

In response to the above issues, we postulate the scoring criteria of the primitive physics problem in accordance with the six representations of abstraction, image, assignment, physics, methodology and 
mathematics of the physics problem solving. The criteria of rating are listed as following: " 1 " is assigned if the representation did occur, and " 0 " if it never occurs. That is, the score for each characterization is a dichotomy scoring system, which scores 1 or 0 . For example, for the primitive physical problem of "pushups", in the process of assignment and representation, students need to set the gravity G, arm strength F, arm length $\mathrm{L}$, the angle $\theta$ between the body and the ground, and the work $\mathrm{W}$ done to complete a push-up. In the grading process, students can get 1 point if they completely set the above five physical quantities, and 0 point if any setting is incomplete or incorrect.

Thus, the rating of subjective questions transfers to an objective rating. The full score for each question is 6 points, since each problem is resolved with 6 representations. There are 4 questions in the test, and the final score is 24 . The details of the measuring instrument of primitive physics problem for junior high school students are as follows:

\section{1) The Primitive Physics Problem 1-The Light Bulb Dimming}

When night falls, the power station sends electricity to thousands of households through power lines, and the city is brightly lit. In the peak of electricity consumption at night, incandescent lamps tend to be yellow and dark, while incandescent lamps are offer normal illumination when the voltage is low. Please use the physics knowledge you have learned to set up the physics quantities and explain the phenomenon.

Table 1. Rating Criteria of the Primitive Physics Problem for the Light Bulb Dimming

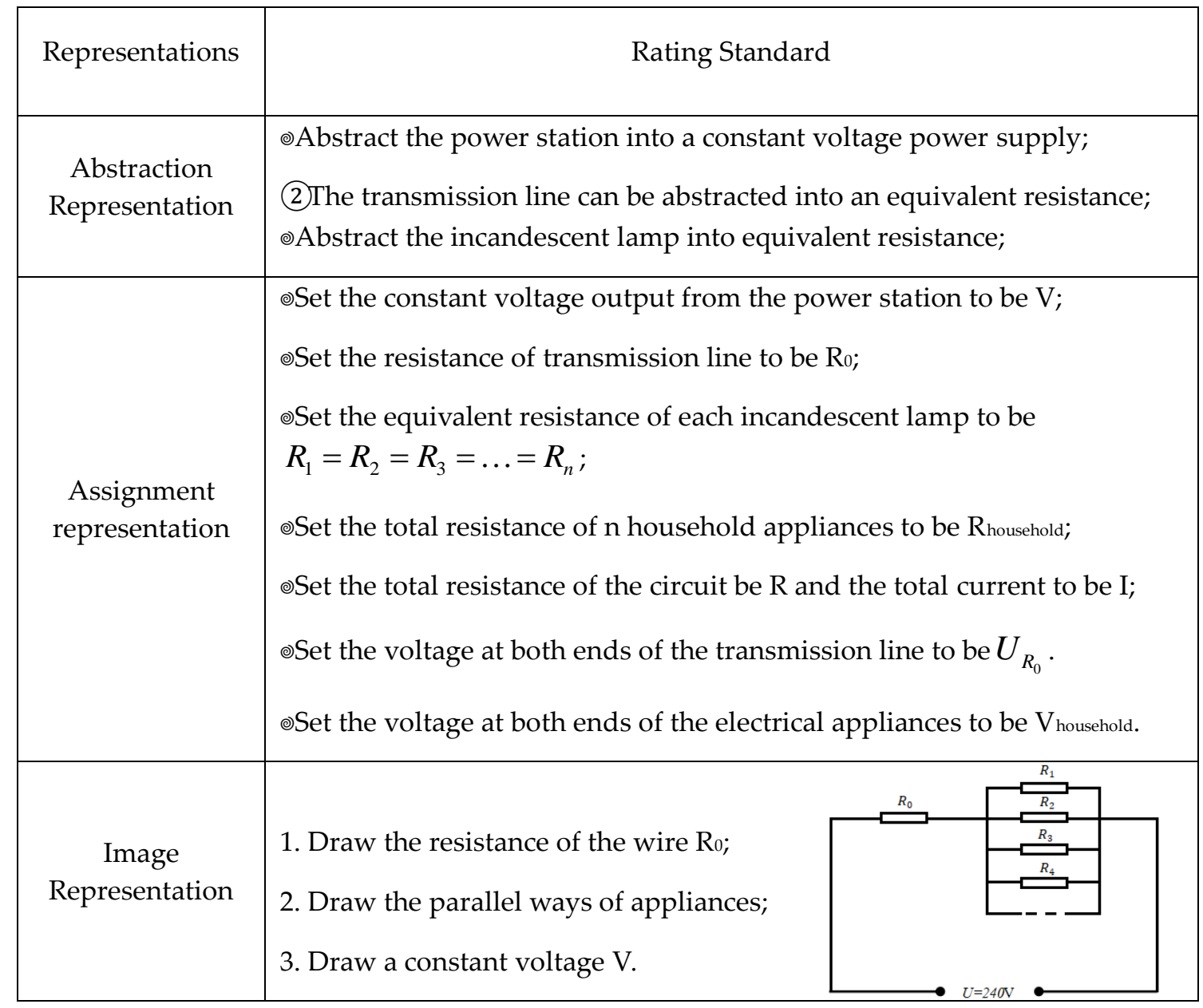




\begin{tabular}{|c|c|}
\hline \multirow{3}{*}{$\begin{array}{c}\text { Physics } \\
\text { Representation }\end{array}$} & $U=I R$ \\
\hline & $1 \quad 1 \quad 1, \frac{1}{1}$ \\
\hline & $R_{\text {household }} \quad R_{1} \quad R_{2} \quad R_{3}{ }^{\cdots} R_{n} \quad U=U_{R_{0}}+U_{\text {household }}$ \\
\hline $\begin{array}{l}\text { Methodology } \\
\text { Representation }\end{array}$ & $\begin{array}{l}\text { ๑Correctly analyze the series-parallel relationship between transmission } \\
\text { line and the appliances; } \\
\text { ๑Correctly analyze the parallel relationship among the equivalent } \\
\text { resistances of the appliances; } \\
\text { ๑Correct analysis of the output voltage of the power station is equivalent } \\
\text { to the sum of the partial pressure of the transmission line and that of the } \\
\text { consumers; }\end{array}$ \\
\hline $\begin{array}{l}\text { Mathematics } \\
\text { Representation }\end{array}$ & $\begin{array}{l}\text { More appliances are used during peak time: } \\
\text { According to: } \\
\frac{1}{R_{\text {household }}}=\frac{1}{R_{1}}+\frac{1}{R_{2}}+\frac{1}{R_{3}}+\ldots \frac{1}{R_{n}} \\
\text { It can be seen that as n increases, the user's equivalent total resistance } \\
\text { Rhousehold decreases. Therefore, the total resistance } R=R_{R_{0}}+R_{\text {household }} \text { of } \\
\text { the circuit becomes smaller; According to: } U=I R \text {, it can be seen that } U \\
\text { does not change, } R \text { decreases, so the trunk current I increases; According } \\
\text { to: } U_{R_{0}}=I R_{0} \text {. It can be seen that the } U \text { remains unchanged, the current I } \\
\text { increases, so that } U_{R_{0}} \text { becomes larger; According to: } \\
U=U_{R_{0}}+U_{\text {household }} \text {, it can be seen that the U remains unchanged, the } \\
U_{R_{0}} \text { becomes larger and the user voltage } U_{\text {household }} \text { decreases; Therefore, } \\
\text { the voltage at both ends of the bulb is lower than the rated voltage of the } \\
\text { bulb in peak time. Finally, the brightness of the incandescent lamp } \\
\text { darkens and the color turns yellow at the same time. Similarly, in the } \\
\text { opposite case, the } R_{\text {household }} \text { becomes larger, the partial voltage at both } \\
\text { ends of the user becomes larger, so that the bulb can emit light normally } \\
\text { when the rated voltage is reached. }\end{array}$ \\
\hline
\end{tabular}

2) The Primitive Physics Problem 2 - The Series-Parallel Bulbs

The lights in public toilets are often clear all night and are therefore extremely vulnerable. An experienced electrician uses a method in which two identical bulbs are connected in a series and then connected to the circuit. Although the brightness of the lamp is reduced, the service life of the bulb can be greatly extended, so that the trouble of frequent lamp replacement can be eliminated. Please use the knowledge you have learned to set up the physics quantities autonomously and explain the phenomenon. 
Table 2. Rating Criteria of the Primitive Physics Problem for the Series-Parallel Bulbs

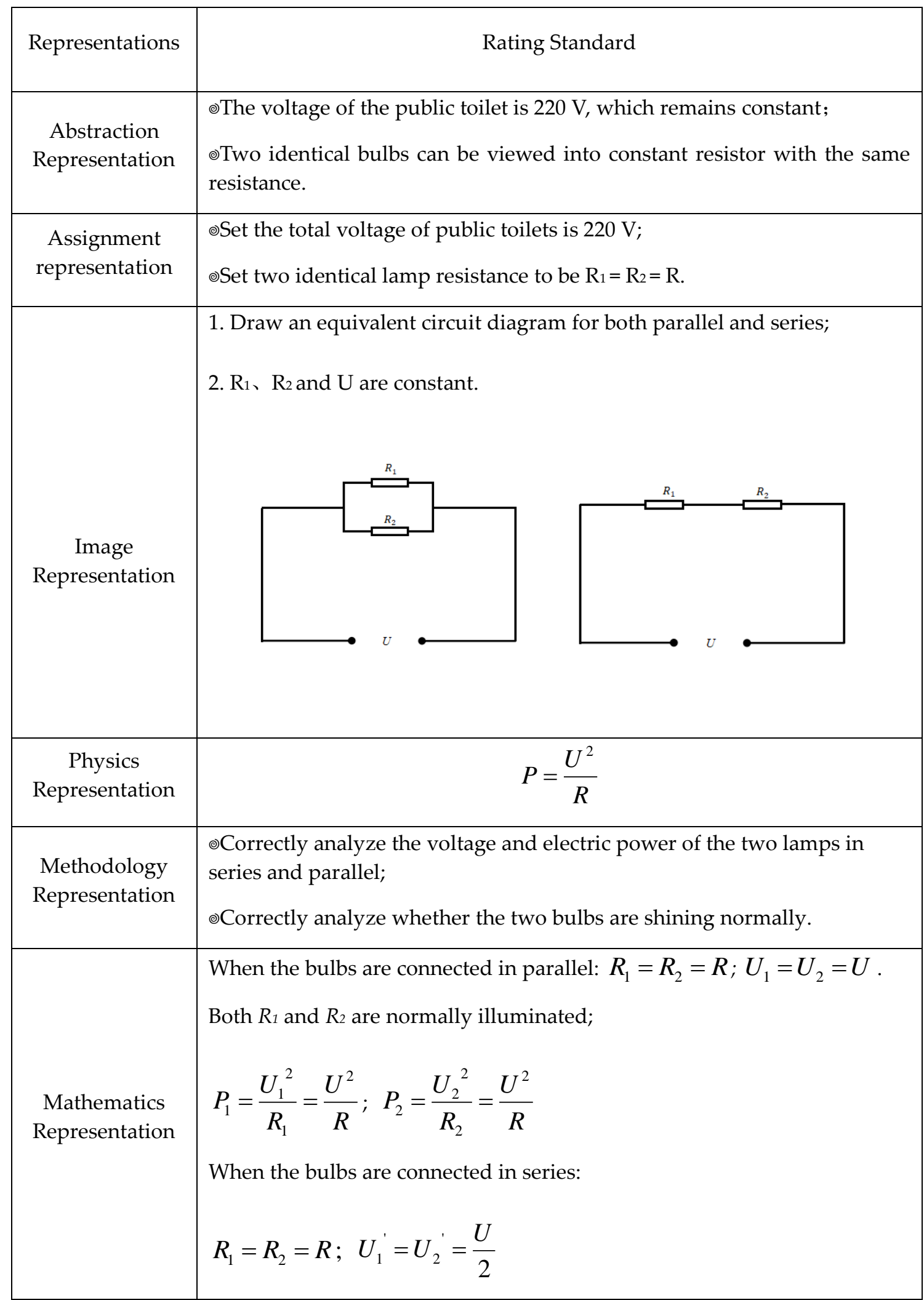




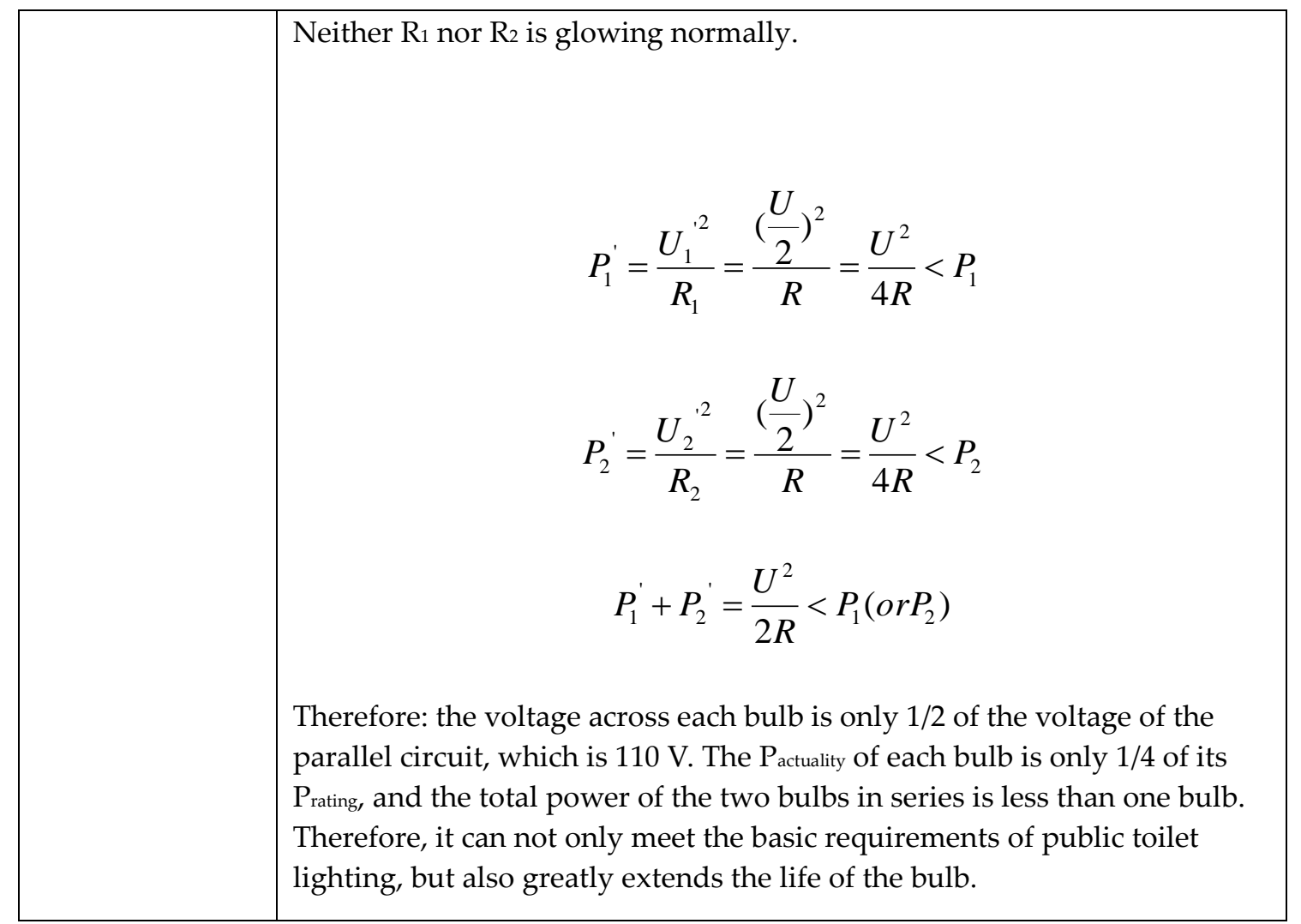

3) The Primitive Physics Problem 3-Clean Sludge in Pond

When the dredging work was completed, the boat which loaded the sludge is still in the water. Is the water surface rising, falling or remaining the same? Please set up the physics quantities autonomously and derive an expression to prove your conjecture.

Table 3. Rating Criteria of the Primitive Physics Problem for Cleaning Sludge in Pond

\begin{tabular}{|c|c|}
\hline Representations & Rating Standard \\
\hline $\begin{array}{c}\text { Abstraction } \\
\text { Representation }\end{array}$ & $\begin{array}{l}\text {-Instead of abstracting the ship as a particle, the volume of the ship } \\
\text { should be considered; } \\
\text { @Instead of abstracting the sludge as a particle, the volume of the } \\
\text { sludge should be considered. }\end{array}$ \\
\hline $\begin{array}{l}\text { Assignment } \\
\text { representation }\end{array}$ & $\begin{array}{l}\text { @Set the ship's gravity to Gship; } \\
\text { @Set the sludge's gravity to Gsludge; } \\
\text { @Set the sludge's volume to Vsludge; } \\
\text { @Set the sludge's density to @sludge; } \\
\text { ๑Set the water's density to @water; }\end{array}$ \\
\hline
\end{tabular}




\begin{tabular}{|c|c|}
\hline & $\begin{array}{l}\text { ๑Set the gravity constant to } g \text {; } \\
\text { ๑Set the volume of the ship immersed in water to } V_{1} \text { before salvaging } \\
\text { the sludge; } \\
\text { ๑Set the volume of the ship immersed in water to } V_{2} \text { after salvaging } \\
\text { the sludge. }\end{array}$ \\
\hline Image Representatic & ludge \\
\hline $\begin{array}{c}\text { Physics } \\
\text { Representation }\end{array}$ & $\begin{array}{l}\text { The floating condition of the object, the floating state, gravity equals } \\
\text { buoyancy. }\end{array}$ \\
\hline $\begin{array}{l}\text { Methodology } \\
\text { Representation }\end{array}$ & $\begin{array}{l}\text { ๑Correctly analyze the gravity and buoyancy of the ship before the } \\
\text { dredging work; } \\
\text { ๑Correctly analyze the gravity and buoyancy of the ship after the } \\
\text { dredging work. }\end{array}$ \\
\hline $\begin{array}{l}\text { Mathematics } \\
\text { Representation }\end{array}$ & 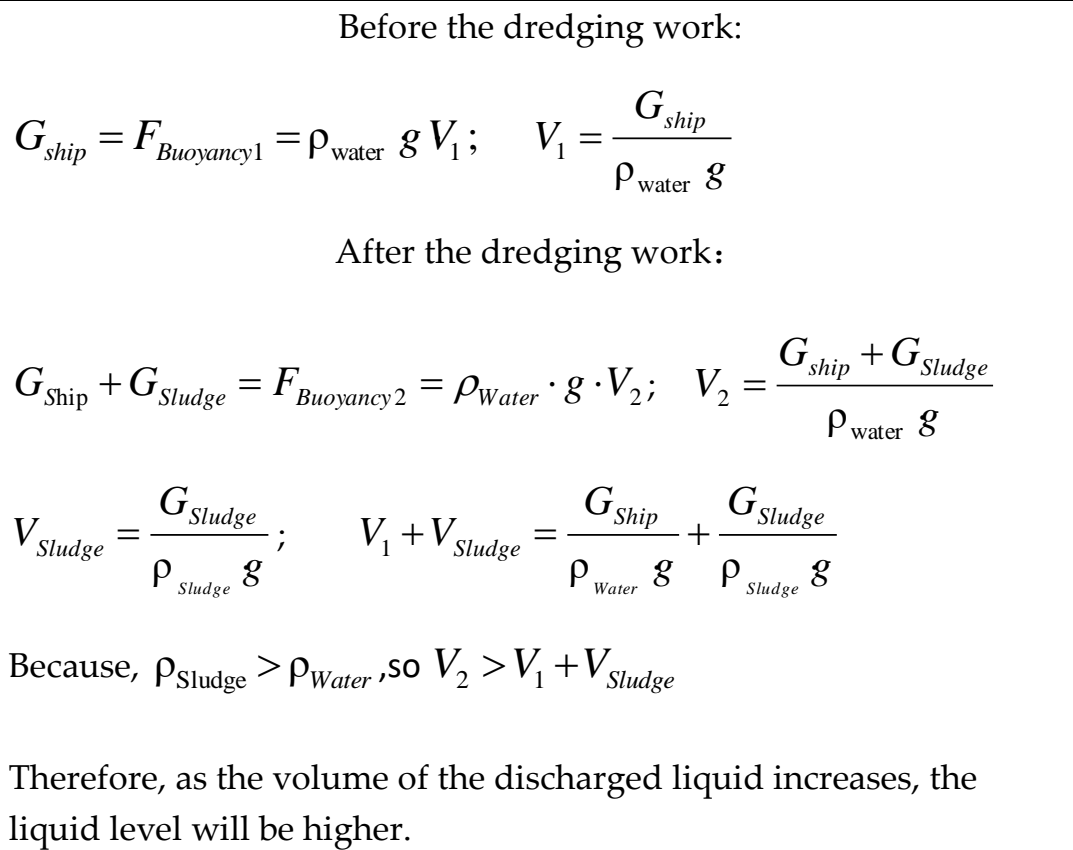 \\
\hline
\end{tabular}




\section{4) The Primitive Physics Problem 4-Push-up}

Male students prefer to do push-ups in daily exercises and physical education classes. Please use the knowledge you have learned to set up the physics quantities independently and deduce the expression of the work done by students in one push-up.

Table 4. Rating Criteria of the Primitive Physics Problem for the Series-Parallel Bulbs

\begin{tabular}{|c|c|}
\hline Representations & Rating Standard \\
\hline $\begin{array}{l}\text { Abstraction } \\
\text { Representation }\end{array}$ & $\begin{array}{l}\text { ๑People are abstracted as leverage; } \\
\text { ๑The human foot is abstracted as a fulcrum. }\end{array}$ \\
\hline $\begin{array}{l}\text { Assignment } \\
\text { representation }\end{array}$ & 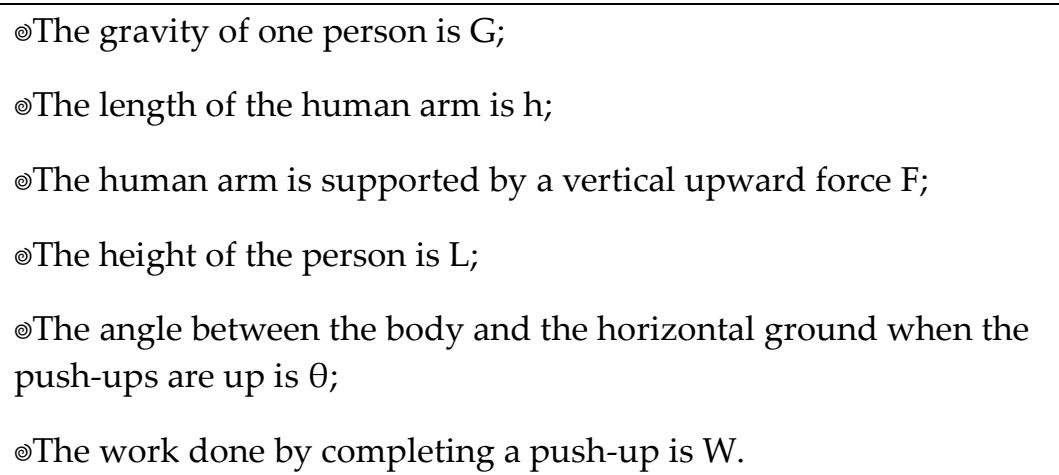 \\
\hline $\begin{array}{l}\text { Image } \\
\text { Representation }\end{array}$ & $\left.h\right|_{G} ^{2}$ \\
\hline $\begin{array}{c}\text { Physics } \\
\text { Representation }\end{array}$ & Leverage equilibrium, the expression for work. \\
\hline $\begin{array}{l}\text { Methodology } \\
\text { Representation }\end{array}$ & $\begin{array}{l}\text { Find the driving force, the lever arm of the driving force, drag force, } \\
\text { the lever arm of the drag force. }\end{array}$ \\
\hline
\end{tabular}




\begin{tabular}{|l|l|}
\hline $\begin{array}{c}\text { Mathematics } \\
\text { Representation }\end{array}$ & $\begin{array}{l}F_{1} \cdot L_{1}=F_{2} \cdot L_{2} \\
F \cdot \sqrt{L^{2}-h^{2}}=G \cdot \sqrt{\left(\frac{L}{2}\right)^{2}-\left(\frac{h}{2}\right)^{2}} \\
\end{array}$ \\
& So, $F=\frac{1}{2} G$ \\
& $W=F S=\frac{1}{2} G h$ \\
\hline
\end{tabular}

\subsubsection{Lawson Classroom Test of Scientific Reasoning (LCTSR)}

Recently, the interest in studying student abilities in scientific reasoning has increased (Cavallo, A. M. L., Rozman, M., Blickenstaff, J., \& Walker, N., 2003; Coletta, V. P., \& Phillips, J. A., 2005; Bao, L., Xiao, Y., Koenig, K., \& Han, J., 2018). Effective assessment tools have been developed by related educators and researchers to evaluate the scientific reasoning abilities of students. For instance, the Piagetian clinical interview was one of the early methods to assess students' formal reasoning abilities. However, it was confirmed that such a method is cost and time intensive for classroom practices (A. E. Lawson, 1978). Thereafter, a number of instruments in assessing scientific reasoning abilities of students have been created, such as the group assessment of logical thinking test (GALT) (V. Roadrangka, R. H. Yeany, \& M. J. Padilla, 1982), the test of logical thinking (TOLT) (K. Tobin \& W. Capie, 1981), and Lawson's classroom test of formal reasoning (CTFR-78) (A. E. Lawson, 1978). The initial open-response version of the CTFR-78 was revised in the year 2000 to become a 24-item multiple choice test (A. E. Lawson, 2000). This most recent version is referred to as the Lawson classroom test of scientific reasoning (LCTSR), and it has gained wide popularity in the education community (Hestenes, D., Wells, M., \& Swackhamer, G., 1992).

Lawson Classroom Test of Scientific Reasoning (LCTSR) was utilized in this paper to assess students' abilities in the following six dimensions: conservation of matter and volume, proportional reasoning, control of variables, probability reasoning, correlation reasoning, and hypothetical-deductive reasoning. Among them, questions 1-4 examine the volume and mass conservation ability, questions 5-8 examine the proportional reasoning ability, questions 9-14 examine the control variable ability, questions 15-18 examine the probability reasoning ability, questions 19 and 20 examine the related reasoning ability, and questions 21-24 examine the deductive reasoning ability. Each question has 1 point, and the total score is 24 points, which is equal to the total score of the original physics problem.

\section{Results}

The developed criteria of the two measurements were independently used by two researchers, who were trained by strict grading. They will discuss and make a final decision together if the result is not consistent. 
Data analyses is performed using SPSS22.0. The difficulty of the measuring instrument was calculated, $\mathrm{H}=0.328$. The result of difficulty demonstrates the measuring instrument of primitive physics problem for junior high school students is moderately difficult. The discrimination of the measuring instrument was calculated, $\mathrm{D}=0.464$, which indicates that the measuring instrument of the primitive physics problem can distinguish students with different abilities. The reliability is computed. The coefficient of Cronbach's Alpha value is 0.907. Nunnally recommended that alpha values should be at least 0.7(J. C. Nunnally., 1978), which suggests a higher degree of consistency among the problems.

\subsection{Confirmatory Factor Analysis}

Further Confirmatory Factor Analysis (CFA) was used to testify the construct validity. Using MPLUS to construct the first-order model, the fitting index of the model is shown in Table 5. Models (e.g., CFA) could be accepted if they met the following requirements: (1) the ratio of $\mathrm{X}^{2}$ and $\mathrm{d} f$ was statistically nonsignificant ( $\mathrm{p}>0.01)$; (2) standardized root-mean-square residual (SRMR) and root-mean-square error of approximation (PMSEM) were smaller than 0.08; and (3) Confirmatory Fit Index (CFI) and gamma hat were greater than 0.90 (Marsh, H. W. , Hau, K. T. , \& Wen, Z. , 2004). We learnt that the values of CFI (0.999) and TLI (0.995) are greater than 0.90 while that of SRMR (0.019a) and RMSEA (0.034) (see Table 5), less than 0.08 , which fit the evaluation index. The result of confirmatory factor analysis implies the fitting index of the model is acceptable.

Table 5. Model fitting index of the primitive physics problem.

\begin{tabular}{cccccccc}
\hline $\mathrm{X}^{2}$ & $\mathrm{~d} f$ & TLI & CFI & AIC & BIC & SRMR & RMSEA \\
\hline $0.392^{*}$ & 3 & 0.995 & 0.999 & 1168.4 & 1233.8 & 0.019 & 0.034 \\
\hline
\end{tabular}

4.2. Heterogeneity analysis between the instrument of primitive physics problem and LCTSR

Exploratory factor analysis was conducted between six sub-dimensions of LCTSR and six characterization dimensions of original physics problems. $\mathrm{KMO}=0.775$, which demonstrates that the data obtained is suitable for principal component analysis. Twelve factors are aggregated into two factors, the total variance is explained as $51.845 \%$, the factor 1 refers to the primitive physics problem, and factor 2 represents LCTSR.

Table 6. Factor Loading on the 12 indicators

\begin{tabular}{ccccccc}
\hline Factor 1 & Abstraction & Assignment & Image & Physics & Methodology & Mathematics \\
\hline $\begin{array}{c}\text { Factor } \\
\text { loading }\end{array}$ & 0.791 & 0.602 & 0.826 & 0.904 & 0.916 & 0.904 \\
\hline Factor 2 & $\begin{array}{c}\text { control of } \\
\text { variables }\end{array}$ & $\begin{array}{c}\text { conservation } \\
\text { of matter and } \\
\text { volume }\end{array}$ & $\begin{array}{l}\text { hypothetical } \\
\text {-deductive } \\
\text { reasoning }\end{array}$ & $\begin{array}{c}\text { probability } \\
\text { reasoning }\end{array}$ & $\begin{array}{c}\text { correlation } \\
\text { reasoning }\end{array}$ & $\begin{array}{c}\text { proportional } \\
\text { reasoning }\end{array}$ \\
\hline $\begin{array}{c}\text { Factor } \\
\text { loading }\end{array}$ & 0.579 & 0.399 & 0.591 & 0.637 & 0.610 & 0.319 \\
\hline
\end{tabular}

As illustrated in Table 6, the six factors, including abstraction, imagination, assignment, physics, methodology and mathematics, loadings were found between 0.602 and 0.904 on the factor-primitive 
physics problem. The other six factors, including control of variables, conservation of matter and volume, hypothetical-deductive reasoning, probability reasoning, correlation reasoning and proportional reasoning, loadings were calculated from 0.319 to 0.637 . The correlation coefficient between factor 1 and factor 2 was estimated to be 0.322 , showing a low correlation between the two instruments. The data shows that the instrument of primitive physics problem and LCTSR represents students' different abilities separately. In other words, the ability of solving the primitive physics problem is different with the ability of scientific reasoning.

\section{Discussion and conclusions}

Based on the analysis of the data, we found that the measuring instrument of primitive physics problem for junior high school students has moderate difficulty and good discrimination, and the problems are closely related to the real situation, have a strong interest and openness, and can stimulate the students' aspiration to knowledge. Moreover, the instrument also has high reliability and validity, which made it possible to effectively identify students' ability to solve physics problems, and avoid to the problem that the objective test cannot accurately assess students' ability to solve physics problems.

Initial attempts have been made to measure the developmental level of learners (Bart, W. M., 1971; Docktor, J. L., Strand, N. E., José P. Mestre, \& Ross, B. H., 2015). Although different kinds of contributions have been made in previous studies, some drawbacks still exist, such as the loss of motivating aspects and the sense of meaningfulness that arise from physical materials and equipment (A. E. Lawson, 1978). The instrument developed in this paper has important value. In the compilation of the measuring instrument of primitive physics problem for junior high school students, we were dedicated to the objective research of scoring criteria on the basis of referring to various rating criteria. The primitive physics problem was combined with the objective rating, and the scoring criteria of Objectively Evaluating Subjective Questions was developed. The instrument not only retains the characteristics that subjective questions can truly assess students' ability to solve physics problems, but also eliminates the interference of subjective factors on subjective test scores, which has made new progress in the compilation of measuring instruments for solving physics problems. Furthermore, the significance of the scoring criteria of Objectively Evaluating Subjective Questions lies in that it establishes objective and fair evaluation criteria for the primitive physics problem measuring instruments. Additionally, it provides a reference for the compilation of relevant instruments.

From the perspective of the theoretical, the representational theory of the primitive physics problem was proved to be effective, which may promote the development of educational theory. According to psychologists' research on representation theory, the traditional view regards problem representation as the internal psychological structure of problem solver, including internal knowledge, structure and neural network. In recent years, it has been found that the presentation of problems and the composition and structure of problem situations also have independent influences, constraints or decisions on problem solving behavior. Therefore, problem representation can be divided into external representation and internal representation. External representation is defined as the composition and structure of problem situation, including physical symbols, objects, dimensions, and external rules, constraints or boundary conditions. Internal representation is the knowledge and structure of problem solver's memory system, such as proposition, schema, neural network and other types (Docktor, J. L., Strand, N. E., José P. Mestre, \& Ross, B. H., 2015). The primitive physical problem unifies the internal and external representations. According to the definitions of external representation and internal representation, abstraction 
representation, assignment representation and image representation in original problem solving belong to external representation, while physics representation, methodology representation and mathematics representation belong to internal representation.

More importantly, as a new kind of problem, the primitive physics problem not only maintains a true description of the physical phenomenon, but also can be used as a tool to monitor and examine the complete process of solving the physical problem of students. This coincides with the conceptional shifts in the Next Generation Science Standard (NGSS) (Bao, L., Cai, T., Koenig, K., Fang, K., \& Wu, N., 2009). Development of general scientific abilities, which will promote students' ability to handle open-ended real-world tasks successfully in their future careers, is one of the goals of STEM education. Scientific reasoning, as such ability, representing a set of general skills involved in science inquiry supporting the experimentation, evidence evaluation, inference and argumentation that lead to the formation and modification of concepts and theories about the natural and social world (Zimmerman, C., 2007). LCTSR is universally accepted as a standardized instrument to measure the scientific reasoning ability of students. Typical research as implemented by Bao et al. (Bao, L., Cai, T., Koenig, K., Fang, K., \& Wu, N., 2009), LCTSR was applied in their work to assess student scientific reasoning ability, Force Concept Inventory (FCI) and the Brief Electricity and Magnetism Assessment (BEMA)(Lin, D. , Ruth, C. , Bruce, S. , \& Robert, B. , 2006), which were widely recognized assessment tools used to assess students' learning of specific physics concepts, to study the possible causal interactions between science content learning and scientific reasoning. They found that there exists a high correlation between FCI and BEMA and small correlations between LCTSR and FCI/BEMA. This finding can be used as important evidence for our research.

According to Gardner's theory of multiple intelligences, the low correlation between scientific reasoning ability and primitive physical problem-solving ability shows that they belong to different intelligences to a great extent, and intervention of one intelligence does not necessarily have an impact on the other. The ability to solve the primitive physics problem, as a special ability from that of scientific reasoning, has the potential to become important indicators in measuring the level of students' physics learning. We are not suggesting to replace LCTSR with the instrument of the primitive physics problem. We expect that the two instruments can play an important role in distinguishing students' general and special abilities, respectively.

Representational theory of the primitive physics problem can also provide useful enlightenment for teaching practice. The application of primitive physics problems can effectively promote the development of students' physical thinking. Indeed, Behind each representation there is a corresponding form of thingking (see Table 7).

Table 7. The correspondence between representational level and thinking form

\begin{tabular}{|c|c|c|}
\hline $\begin{array}{c}\text { Representational } \\
\text { level }\end{array}$ & Thinking form & Interpretation \\
\hline Abstraction & Abstraction & Abstracting prototype from life into a model \\
\hline Assignment & hypothesis & $\begin{array}{c}\text { Hypothesizing the relevant physical quantities } \\
\text { according to the needs of solving the problem }\end{array}$ \\
\hline Image & Image & $\begin{array}{c}\text { Using image thinking to draw physical images } \\
\text { to aid understanding }\end{array}$ \\
\hline
\end{tabular}

REAL 2021, 6(1) 


\begin{tabular}{|c|c|c|}
\hline Physics & Generalization & $\begin{array}{c}\text { Search and select physical concepts, laws or } \\
\text { formulas related to problem solving in mind }\end{array}$ \\
\hline Methodology & Model & $\begin{array}{c}\text { Establishing physical model with scientific } \\
\text { method }\end{array}$ \\
\hline Mathematics & reasoning & The physical model is calculated and deduced \\
\hline
\end{tabular}

It can be seen from table 7 that the solving process of primitive physics problem is actually the process of students' thinking activities. In this way, by solving the primitive physical problem, students can not only learn how to carry out abstract representation, assignment representation, image representation, physical representation, methodology representation and mathematics representation, but also learn how to use abstract, hypothesis, image, generalization, model and reasoning to solve real problems. In this sense, the primitive physical problem have the dual role of promoting students' ability of physical problem representation and physical thinking, which further highlights the necessity of the establishment of the primitive physics problem measurement.

Funding: "This research was funded by the General Project of Education of the National Social Science Foundation of China: "Research on the Composition and Performance of Key Competence, grant number BBA190024"

Acknowledgments: The authors gratefully acknowledge the editor of REAL for his invaluable suggestions, and the fruitful advices of Minghua Chen at the Keyan Middle School at Zhejiang Province in China, which elevate the quality of this paper.

Conflicts of Interest: The authors declare no conflict of interest.

\section{References:}

A. E. Lawson. (1978). The development and validation of a classroom test of formal reasoning. Journal of Research in Science Teaching, 15, 11-24.

A. E. Lawson. (2000). Lawson classroom test of scientific reasoning. Retrieved from "< http://www.public.asu.edu/ anton1/AssessArticles/Assessments/Mathematics\$ \%20Assessment s/Scientific $\backslash \% 20$ Reasoning $\backslash \% 20 \$ T$ est.pdf $>$

Ainsworth, S. (2006). Deft: a conceptual framework for learning with multiple representations. Learning \& Instruction, 16(3), 183-198.

Bao, L., Cai, T., Koenig, K., Fang, K., \& Wu, N. (2009). Physics learning and scientific reasoning. Science, 323(5914), 586-587.

Bao, L., Xiao, Y., Koenig, K., \& Han, J. (2018). Validity evaluation of the lawson classroom test of scientific reasoning. Physical Review Special Topics - Physics Education Research, 14(2), 20106-20101.

Boqin Liao \& Xiting Huang. (1997). Experimental Research on the Representation Level of College Students' Solving Physics Problems. Psychological Science, 06, 494-574.(In Chinese)

REAL 2021, 6(1)

DOI: https://doi.org/10.37906/real.2021.1 
Bart, W. M. (1971). The factor structure of formal operations. British Journal of Educational Psychology, 41(1), 70-79.

Cavallo, A. M. L., Rozman, M., Blickenstaff, J., \& Walker, N. (2003). Learning, reasoning, motivation, and epistemological beliefs. Journal of College ence Teaching, 33(3), 18-23.

Coletta, V. P., \& Phillips, J. A. (2005). Interpreting fci scores: normalized gain, preinstruction scores, and scientific reasoning ability. American Journal of Physics, 73(12), 1172-1182.

Docktor, J. L., Strand, N. E., José P. Mestre, \& Ross, B. H. (2015). Conceptual problem solving in high school physics. Physical Review Special Topics Physics Education Research, 11(2), 020106.

D.P. Simon, \& H. A. Simon. (1978). Individual differences in solving physics problems. In R. S. Siegler (Ed.). Children's thinking: What develops? Hillsdale, NJ, US: Lawrence Erlbaum Associates, Inc., 325348.

Enghag, M., Gustafsson, P., \& Jonsson, G. (2007). From everyday life experiences to physics understanding occurring in small group work with context rich problems during introductory physics work at university. Research in ence Education, 37(4), 449-467.

Goldstein, E. Bruce. (2010). Cognitive psychology:connecting mind, research, and everyday experience. Wadsworth, USA, 6.

Heller, P., \& Heller, K. (1999). Cooperative Group Problem Solving in Physics, 53-60. http://groups.physics.umn.edu/physed/Research/CGPS/Green\%20Book/chapter4.pdf

Hestenes, D., Wells, M., \& Swackhamer, G. (1992). Force concept inventory. Physics Teacher, 30(3), 141-158.

Hongjun Xing, Yao Shi (2016). Teaching of Primitive Physics Problem: Genesis of A native teaching theory. Education Research Monthly, 33(9): 83-90. (In Chinese)

Hongjun Xing, Qingmei Chen (2005). On the educational value of Primitive Physics Problem and the enlightenment to physics education. Curriculum, Teaching Material and Method, 25(1): 56-61. (In Chinese)

Hongjun Xing (2007). Primintive Problem Teaching: The new horizon of physical education reform. Curriculum,Teaching Material and Method, 27(5): 51-57. (In Chinese)

J. C. Nunnally. (1978). Psychometric theory (2nd ed.). New York: McGraw-Hill.

J. De Kleer. (1977). Multiple representations of knowledge in a mechanics problem solver. Proceedings of the 5th Internatuinal Joint Conference on Artificial Intelligence. Cambridge, Mass.: MIT Press.

Johsua, S., \& Dupin, Jean-Jacques. (1991). In physics class, exercises can also cause problems. International Journal of Science Education, 13(3), 291-301.

K. Tobin \& W. Capie. (1981). The development and validation of a group test of logical thinking, Educ. Psychol. Meas. 41, 413.

Larkin, J H. (1985). Understanding, problem representations, and skill in physics. Thinking and Learning Skills (Lawrence Erlbaum Associates, Hillsale, NJ), 2:141-159.

Lin, D., Ruth, C., Bruce, S., \& Robert, B. (2006). Evaluating an electricity and magnetism assessment tool: brief electricity and magnetism assessment. Physical Review Special Topics Physics Education Research, 2(1), 010105. 
Marsh, H. W., Hau, K. T., \& Wen, Z. (2004). In search of golden rules: comment on hypothesis-testing approaches to setting cutoff values for fit indexes and dangers in overgeneralizing hu and bentler \"s (1999) findings. Structural Equation Modeling A Multidisciplinary Journal, 11(3), 320341.

McDermott, J, \& Larkin, J H. (1978). Re-representing textbook physics problems. National Conference of the Canadian Society for Computational Studies of Intelligence. Toronto: University of Toronto Press.

Michelene T. H. Chi, Paul J. Feltovich, \& Robert Glaser. (1981). Categorization and representation of physics problems by experts and novices. Cognitive Science, 5(2),121-152.

Rennie, L. J., \& Parker, L. H. (1995). Placing physics problems in real-life context: students' reactions and performance. Australian ence Teachers Journal, 42(1), 55-59.

V. Roadrangka, R. H. Yeany, \& M. J. Padilla. (1982). GALT, Group Test of Logical Thinking (University of Georgia, Athens, GA).

Whitelegg Elizabeth \& Edwards Chris. (2001). Beyond the laboratory-learning physics using real-life contexts. Research in Science Education-Past, Present, and Future. Springer, Dor-drecht, 337-342.

Yerushalmi, E., Henderson, C., Heller, K., Heller, P., \& Kuo, V. (2007). Physics faculty beliefs and values about the teaching and learning of problem solving. I. mapping the common core. Physical Review Special Topics Physics Education Research, 3(2).

Zhu Deng. (2002). The Representation-State Theory of Problem-Solving: Theoretical and Experimental Studies. Nanjing Normal University (Doctor degree).

Zimmerman, C. (2007). The development of scientific thinking skills in elementary and middle school. Developmental Review, 27(2), 172-223. 